\title{
Interferon alfa-2a modifies the course of subfoveal and juxtafoveal choroidal neovascularisation
}

\author{
Claus Engler, Birgit Sander, Jørgen Villumsen, Henrik Lund-Andersen
}

\begin{abstract}
The first double masked placebo controlled trial of interferon alfa-2a for the treatment of overt choroidal neovascular membranes is presented. A total of 43 consecutive patients were randomised to double masked treatment with either interferon alfa-2a, 3 million IU subcutaneously three times a week or matching placebo, for a period of 8 weeks. End of study changes from baseline in distance and near visual acuity, macular visual field, contrast sensitivity, and macular morphology (fluorescein angiography) were assessed. The between group difference in distance visual acuity, the primary efficacy variable, was significant in favour of interferon alfa- $2 a(p=0 \cdot 023)$. Fluorescein angiograms, macular visual fields, and near vision all showed a trend in favour of interferon alfa-2a. It was concluded that, at the dosage used in this study, interferon alfa- $2 a$ is a reasonably well tolerated and apparently effective short term treatment of subfoveal and juxtafoveal choroidal neovascularisations.

(Brf Ophthalmol 1994; 78: 749-753)
\end{abstract}

Age-related macular degeneration (ARMD) has been estimated to affect around $2 \%$ of the population between the ages of 52 to 64 years in industrialised countries. This figure increases to $10 \%$ between the ages of 65 and 74 years and further increases to $30 \%$ between the ages of 74 and 85 years. ${ }^{1}$ As the proportion of elderly people in the population continues to rise, the need for an effective treatment is evident, particularly as the disease is believed to be the leading cause of blindness in the developed world.

Two main types of ARMD are recognised. The more common form, responsible for $80 \%$ of reported cases of the disease, is non-exudative. The second type, though less common, nevertheless accounts for up to $90 \%$ of the cases of severe vision loss attributed to the disease. ${ }^{2}$ This is neovascular or exudative ARMD which is characterised by ingrowth of new vessels from the choroid into the neural retina causing retinal pigment epithelial detachment, haemorrhages, hard exudation, and, later, fibrous tissue formation. ${ }^{3}$ Choroidal neovascular membranes may be well defined (overt) or poorly defined (occult) on fluorescein angiography.

At present, the only invervention of proved value in ARMD is laser photocoagulation of well defined choroidal neovascular membranes. The use of argon laser to treat overt choroidal neovascularisations situated more than $200 \mu \mathrm{m}$ from the foveal centre has been associated with long term prevention of vision loss in several clinical trials with up to 5 years of follow up. ${ }^{47}$ However, the use of lasers is controversial when the neo- vascularisation is situated in or within $200 \mu \mathrm{m}$ of the foveal centre. When subfoveal membranes are photocoagulated, the destructive effects on foveal function results in an initial worsening of visual acuity, benefit being delayed until an average of 18 months after treatment. ${ }^{8}$ For juxtafoveal membranes results showed that $49 \%$ of photocoagulated eyes had a decline by more than 6 lines in visual acuity, while $58 \%$ of untreated eyes had a decline of more than 6 lines.

Furthermore, in occult choroidal neovascularisation (including subfoveal, juxtafoveal, and extrafoveal lesions), laser treated eyes have been shown to have a worse outcome than untreated eyes. ${ }^{9}$ Alternative therapy is thus required for lesions that are unsuitable for laser photocoagulation and for those patients who are not prepared to accept an immediate loss of visual acuity following laser photocoagulation, in exchange for a better chance of less deterioration in the long term. Interest has focused on the inhibition of angiogenic growth factors as a possible means of controlling the neovascular process. $^{10}$

Interferon alfa-2a (Roferon-A), a genetically engineered copy of one of the naturally occurring human interferons, has antiviral, immunoregulatory, and antineoproliferative properties and has been used clinically for many years in the treatment of hepatitis, solid tumours, and haematological malignancies. " More recently it has been used successfully to treat haemangiomas of infancy and childhood, where an antiangiogenic effect has been demonstrated. ${ }^{12}{ }^{13}$ Thus, Fung used interferon-alfa in seven patients with neovascular ARMD, and reported a positive effect on visual acuity in six of the seven patients who were treated over a 6-8 week period..$^{14}$ Other minor, uncontrolled trials have produced equivocal results, ${ }^{15}{ }^{16}$ emphasising the need for a controlled evaluation of the effect of interferon alfa-2a in patients with neovascular ARMD. This is the first report of a double masked, placebo controlled trial of interferon alfa- 2 a for the treatment of overt subfoveal and juxtafoveal choroidal neovascularisations.

\section{Patients and methods}

STUDY DESIGN

This double masked, placebo controlled investigation of the effect of interferon alfa- $2 a$ on the course of overt subfoveal and juxtafoveal choroidal neovascularisation, was conducted at the Department of Ophthalmology, Gentofte Hospital, University of Copenhagen. The study was approved by the Danish National Board of Health and the local medical ethics committee and all patients gave their written informed consent. 
INCLUSION CRITERIA

Consecutive patients with a visual acuity better than or equal to $20 / 400$ and overt subfoveal or juxtafoveal choroidal neovascular membranes $0 \mu \mathrm{m}$ to $200 \mu \mathrm{m}$ from the centre of the foveal avascular zone, without fibrous tissue formation demonstrated on stereo fluorescein angiography, were enrolled.

\section{EXCLUSION CRITERIA}

Patients previously treated with interferons or who had received laser photocoagulation were excluded. Patients suffering from serious systemic disease (that is, gastrointestinal disease, ischaemic or incompensated heart disease, kidney disease, liver disease, and/or haematological disease) or psychiatric disorders or epilepsia were also excluded. Finally, patients with other eye diseases apart from ARMD were excluded.

Before inclusion in the study, all patients provided a detailed medical history and venous blood samples (haemoglobin, leucocyte count, white cell differential, platelet count, alkaline phosphatase, bilirubin, prothrombin, lactate dehydrogenase, aspartate aminotransferase, electrolytes, creatinine, and albumin) to rule out systemic conditions that would contraindicate treatment with interferon alfa-2a.

The patients were randomised in blocks of four, to 8 weeks' double blind treatment with either $1 \mathrm{ml}$ interferon alfa-2a, 3 million IU per $\mathrm{ml}$, three times a week, or matching placebo (saline solution $1 \mathrm{ml}$ ), by a member of the staff who also was responsible for preparing the injections but who was not otherwise involved in the study. The injections were packed identically in boxes containing one syringe and labelled with the patient number. Nurses who were not involved in patient evaluation collected the syringes immediately before injection, and administered them subcutaneously, preferably in the evenings to minimise side effects. These nurses also recorded all concurrent symptoms (physical and psychological) described by the patient, either spontaneously or in response to non-leading questioning, at each visit. All patients were instructed to take paracetamol $1 \mathrm{~g}$ three times daily during the treatment period as prophylaxis against the acute side effects of interferon alfa-2a, such as headache and flu-like symptoms. In order to minimise the possibility of unmasking the study, staff involved in patient evaluation were not aware of the symptoms recorded by the nurses who administered the treatment.

Routine haematology and biochemistry, and full ophthalmic examination comprising distance

Table 1 Patient characteristics

\begin{tabular}{lll}
\hline & $\begin{array}{l}\text { Interferon alfa-2a } \\
(n=22)\end{array}$ & $\begin{array}{l}\text { Placebo } \\
(n=20)\end{array}$ \\
\hline $\begin{array}{l}\text { No of patients: } \\
\text { Male }\end{array}$ & 13 & \\
$\quad$ Female & 9 & 12 \\
$\begin{array}{l}\text { Age (years): } \\
\quad \text { Mean }\end{array}$ & & 8 \\
$\quad$ Range & $73 \cdot 3$ & $72 \cdot 5$ \\
Visual acuity: & $47-82$ & $44-83$ \\
$\quad$ Mean & & \\
Range & $20 / 129$ & $20 / 130$ \\
\hline & $20 / 25-20 / 400$ & $20 / 25-20 / 400$ \\
\hline
\end{tabular}

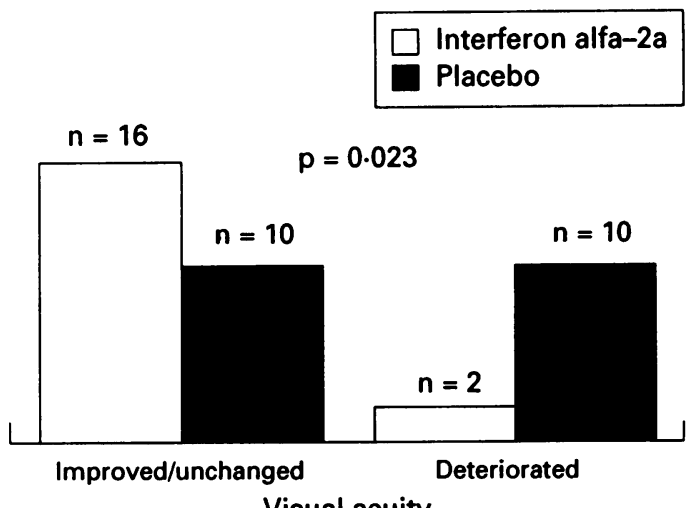

Visual acuity

Figure 1 Effect of treatment with interferon alfa-2a or placebo on distance visual acuity.

and near visual acuity, macular visual field, stereo fluorescein angiography, contrast sensitivity, and Amsler test, were performed 1-3 days before the first administration of the study medication and repeated $1-3$ days after the end of the 8 week treatment period. In addition, patients were asked, at the beginning and at the end of the study, to complete a questionnaire covering various aspects of daily life.

\section{ASSESSMENTS AND ANALYSES}

Best refracted distance visual acuity and central visual ability were measured at $85 \mathrm{~cd} / \mathrm{mm}^{2}$ illumination using, respectively, a standard logarithmic chart with five letters to each line and equal change in visual angle between the lines (CSV-1000, ETDRS test-screen, Vector Vision, Dayton, $\mathrm{OH}, \mathrm{USA}$ ) and a contrast sensitivity chart (CSV 1000E). Near visual acuity was measured with a standard reading chart. Central visual field was tested by means of a Humphrey computer assisted field analyser, model 640 (Allergan, San Leandro, CA, USA) which utilised a macular threshold strategy and was supplied with a standard Amsler recording chart to detect scotomas and distortions on near vision.

Macular morphology was determined by direct ophthalmoscopy, slit-lamp and 60-D lens examination, stereo fundus photography and stereo fluorescein angiography (Canon VF-65U), at both 30 and 60 degrees. The fundus photographs and the fluorescein angiograms were masked and evaluated for presence of oedema, extent of the neovascular membrane, and degree of early and late fluorescein leakage, by two independent, experienced observers who were unaware of the chronological sequence of the photographs.

The primary efficacy variable was distance visual acuity, where an improvement or deterioration of six letters or more (more than one line) was considered clinically relevant. Supporting measures of efficacy included near visual acuity (improvement/deterioration defined as a change of two lines or more) macular visual field (improvement/deterioration defined as a change in threshold of $3 \mathrm{~dB}$ or more), macular morphology (improvement/deterioration defined as a decrease or enlargement of neovascular membrane, more or less hyperfluorescence on fluorescein angiography) and contrast sensitivity (improvement/deterioration defined as a change 
Table 2 Effect of treatment with interferon alfa-2a or placebo on secondary efficacy variables

\begin{tabular}{|c|c|c|c|c|c|c|c|}
\hline \multirow[b]{3}{*}{ Efficacy variable } & \multicolumn{6}{|c|}{ Number of patients } & \multirow{3}{*}{$\begin{array}{l}\text { p Value for } \\
\text { difference } \\
(95 \% C I)\end{array}$} \\
\hline & \multicolumn{2}{|c|}{ Improved } & \multicolumn{2}{|c|}{ Unchanged } & \multicolumn{2}{|c|}{ Deteriorated } & \\
\hline & $\bar{I}$ & $P$ & $I$ & $P$ & $\vec{I}$ & $P$ & \\
\hline Near vision (2 lines) & 1 & 0 & 13 & 13 & 4 & 7 & $\begin{array}{l}0.5 \\
(-14 \% \text { to } 42 \%)\end{array}$ \\
\hline Macular visual field $(3 \mathrm{~dB})$ & 0 & 0 & 11 & 8 & 4 & 8 & $\begin{array}{l}0.3 \\
(-10 \% \text { to } 57 \%)\end{array}$ \\
\hline Fluorescein angiograms ${ }^{\star}$ & 6 & 1 & 6 & 6 & 6 & 11 & $\begin{array}{l}0 \cdot 2 \\
(-4 \% \text { to } 59 \%)\end{array}$ \\
\hline Patients' subjective evaluation & 2 & 2 & 14 & 10 & 2 & 8 & 0.09 \\
\hline
\end{tabular}

$\mathrm{I}=$ Interferon alfa-2a, $\mathrm{P}=$ placebo.

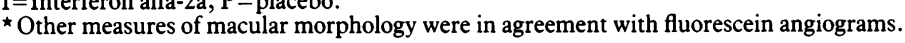

of two steps or more on each row). In addition, the patients' subjective impression of improvement/deterioration was evaluated from a questionnaire covering everyday aspects of life, in particular from the question, 'summary, how is your situation today compared with your situation before the beginning of your eye

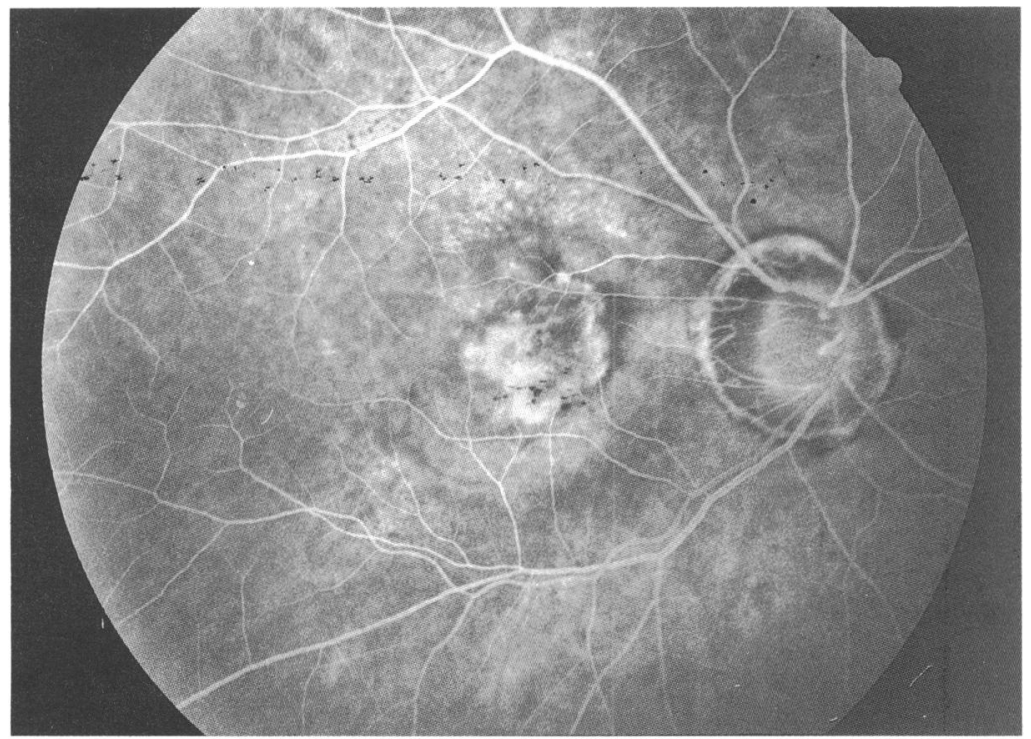

Fig $2 A$

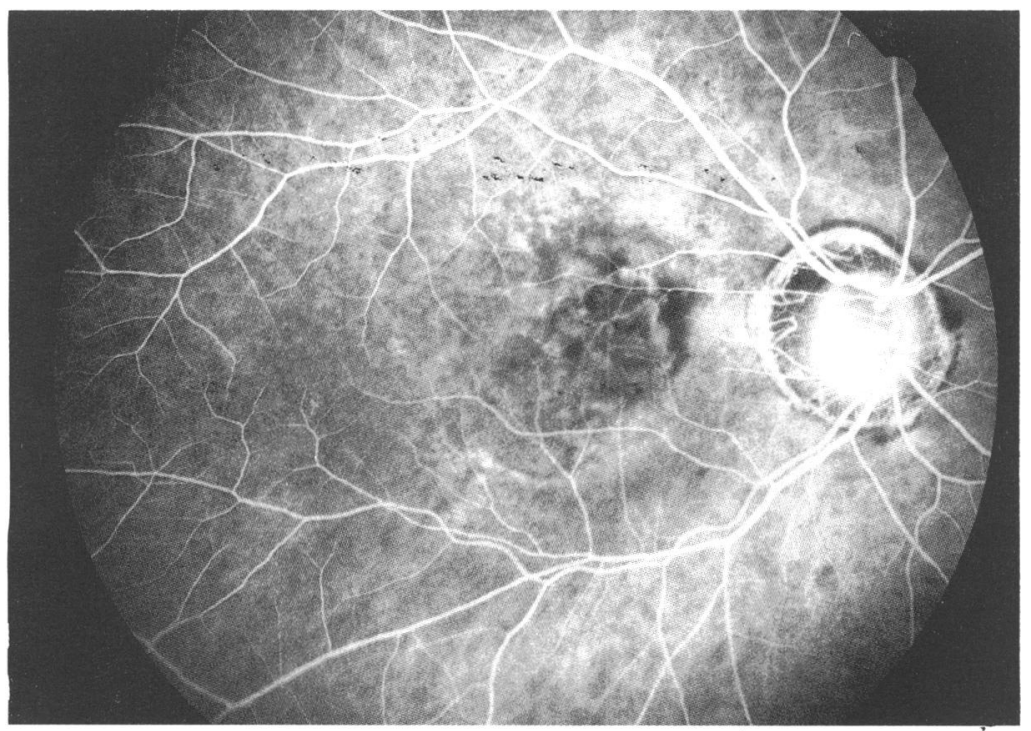

Fig $2 B$

Figure 2 Fluorescein angiograms of smaller overt choroidal neovascularisation before $(A)$ and after (B) treatment. disease', which was answered on a scale from 1 (very deteriorated) to 7 (unchanged). Between group differences were analysed using Fisher's exact significance test (two tailed), declared significant at the level $\mathrm{p}<0.05$, and the $95 \%$ confidence intervals (CI) for the difference were calculated.

Adverse events were compared between treatment groups but no statistical tests were performed on these data.

\section{Results}

A total of 43 consecutive patients were enrolled in the study, 22 of whom were allocated to treatment with interferon alfa-2a and 21 to placebo. The two groups were well matched with respect to age, sex, and visual acuity (Table 1). Four patients in the interferon alfa-2a group were excluded from the efficacy analysis; they terminated the study early, two because of side effects (minor flu-like symptoms) within the first week, one because of intercurrent illness (appendicitis requiring surgery) after 6 weeks, and one because of social problems within the first week. One patient in the placebo group was excluded since she did not complete the refraction and visual acuity testing.

Distance visual acuity was improved or unchanged in 16 patients in the interferon alfa-2a group compared with 10 in the placebo group, and worsened in only two patients in the interferon alfa-2a group compared with 10 in the placebo group (Fig 1). The difference was statistically significant in favour of interferon alfa-2a $(p=0.023 ; 95 \% \mathrm{CI}, 13 \%$ to $65 \%)$.

Changes in near visual acuity, macular visual field, macular morphology (fluorescein angiograms), and patients' subjective evaluation of improvement/deterioration favoured interferon alfa-2a but the between group differences did not reach statistical significance (Table 2 ).

The results of tests for contrast sensitivity and Amsler chart were largely unchanged in both groups.

Adverse events were reported by $(86 \%)$ of patients in the interferon alfa-2a group and (29\%) of patients in the placebo group. They were mild in the majority of cases and most commonly included flu-like symptoms in the first 1 to 2 weeks after the start of treatment with interferon alfa-2a and fatigue during treatment. There was one serious possible adverse event; the patient had an epileptic seizure 48 hours after injection of interferon alfa-2a during the sixth week of the study. He was withdrawn from treatment but included in the efficacy analysis.

Two patients in the interferon alfa-2a group recorded minor deviations in laboratory variables, specifically, elevated aspartate aminotransferase in one, and decreased haemoglobin and albumin in the other, all of which returned to normal after the conclusion of treatment and were not clinically significant. One patient in the placebo group had elevated basic phosphatase and was sent for further medicál examination.

\section{Discussion}

In this short term double masked placebo con- 
trolled trial, interferon alfa-2a significantly preserved or improved visual acuity, when compared with placebo, in patients with subfoveal or juxtafoveal choroidal neovascularisation $(\mathrm{p}=0.023)$. In addition, between group comparisons of reading visual acuity, macular visual field, and macular morphology (fluorescein angiograms) all showed a trend in favour of interferon alfa-2a. The fact that patients' subjective assessment of improvement or deterioration also favoured interferon alfa-2a is consistent with the previous finding that functional performance is closely correlated with measured visual acuity in patients with poor visual acuity secondary to complications of neovascular macular disease. ${ }^{17}$ The more subtle tests of contrast sensitivity and Amsler chart reading were largely unchanged in both groups, but this is not surprising as the very poor visual acuity of many of the patients in this study precluded them from cooperating fully with these tests.

The inclusion criteria in this trial were strict (overt subfoveal or juxtafoveal membranes and visual acuity better than or equal to $20 / 400$ ) in order to exclude patients with the oldest lesions, but the possibility that at least some of the patients were out of therapeutic range cannot be ruled out. There appeared to be a connection between visual acuity at inclusion and effect of treatment, with better results seen in those with a visual acuity of $20 / 125$ or better, though the number of patients makes this observation insignificant. Similarly, smaller (and presumably therefore newer) neovascular membranes seemed to respond better than larger (and presumably older) ones (Fig 2). Early intervention with interferon alfa-2a may be desirable, as the longer a neovascular membrane exists, the more it alters its characteristics from those of a capillary bed towards those of arterioles and venules. ${ }^{1819}$

This is the first double masked, placebo controlled trial of interferon alfa-2a in ARMD to be reported, and the optimum dosage and duration of treatment have not been investigated. It is possible that even greater benefit might have been obtained if treatment had continued beyond the 8 week span of this study. Indeed, Bressler et $a l^{2}$ have shown that approximately $50 \%$ of patients with this condition will lose 3 lines or more of visual acuity within 6 to 11 months. Thus, if the effect observed in the present study following interferon alfa-2a treatment in preserving vision is maintained during a longer treatment period, more significant benefits of the treatment might be seen. The well documented side effects of interferon alfa- $2 a$, which are largely dose related," might limit the use of higher doses or other injection schedules. Side effects in the present study were mild and generally controlled by the administration of paracetamol. There were no cases of haematological toxicity and no patients showed signs of the interferon associated retinopathy (cotton wool spots in the posterior pole) which has been reported by one author. ${ }^{20}$ Thus, the dosage of 3 million IU subcutaneously three times a week, produced adverse events in $86 \%$ of patients (compared with $29 \%$ of patients on placebo) and only three withdrawals (14\%). In a previous uncontrolled study of 20 patients with subfoveal choroidal neovascularisation, the use of the higher dosage of 1.5 to 3.0 million IU per $\mathrm{m}^{2}$ of body surface area subcutaneously or intramuscularly on alternate days, was associated with side effects in all patients and a high incidence $(25 \%)$ of withdrawals due to side effects. ${ }^{16}$

On the basis of this short term study, interferon alfa-2a appears to be an effective and well tolerated treatment for overt subfoveal and juxtafoveal choroidal neovascularisations. It is reasonable to suppose that interferon alfa-2a might be of benefit in the treatment of both parafoveal choroidal neovascularisation and occult neovascular membranes. Large scale studies with long term follow up are required to determine whether a longer duration of treatment, higher dosages or other injection schedules can further improve efficacy without adversely affecting the safety and tolerability profile.

Most choroidal neovascular membranes occur near to, or progress towards, the fovea. ${ }^{21}{ }^{22}$ Laser photocoagulation is thus unsuitable or far from ideal because it results in acute loss of central vision. ${ }^{8}$ Furthermore, the recurrence rate for successfully photocoagulated neovascular membranes is high, of the order of $60 \% .^{23}$

Interferon alfa-2a, either as monotherapy or as a supplement to laser photocoagulation, could represent a major breakthrough for the medical treatment of a disease which is becoming an increasing problem in the industrialised countries.

We thank clinical photographer Hans-Henrik Petersen for skilful photography.

1 Ponte I, Giuffre G. Epidermiology and the future of age-related macular degeneration. New Trends in Ophthalmology V 1990 macular

2 Bressler NM, Bressler SB, Fine SL. Age-related macular degeneration. Surv Ophthalmol 1988; 32: 375-413.

3 Vinding T. Occurrence of drusen, pigmentary changes and exudative changes in the macula with reference to agerelated macular degeneration: an epidemiological study of 1000 aged individuals. Acta Ophthalmol 1990; 68: 410-14

4 Macular Photocoagulation Study Group. Treatment of senile macular degeneration; results of a randomized trial. Arch Ophthalmol 1982; 100: 912-8.

5 The Moorfields Macular Study Group. Treatment of senile macular degeneration: a single-blind randomised trial by argon laser photocoagulation. Br 7 Ophthalmol 1982; 66: 745-53.

6 Coscas G, Soubrane G. Indications, techniques et resultats de la photocoagulations au laser a argon des neovaisseaux sousretiniens maculaires. 7 Fr Ophtalmol 1984; 7: 99-105.

7 Soubrane G, Coscas G, Baudouin C, Koenig F. Randomized study of the photocoagulation with blue-green laser in subretinal neovascularizations of senile macular degeneration, year follow up. Bull Soc Ophtalmol Fr 1987; 87: 249-50.

8 Macular Photocoagulation Study Group. Laser photocoagulation of subfoveal neovascular lesions in age-related macular degeneration: results of a randomized clinical trial. Arch degeneration: results of a rand
Ophthalmol 1991; 109: 1220-31.

9 Soubrane G, Coscas G, Francais C, Koenig F. Occult subretinal new vessels in age-related macular degeneration, natural history and early laser treatment. Ophthalmology 1990; 97: 649-57.

10 Schweigerer L. Anti-angiogenesis as a new concept for the therapy of neovascular diseases. Klin Wochenschr 1991; 69: 417-8

11 Baron S, Tyring SK, Fleischmann R, Coppenhaver DH Niesel DW, Klimpel GR, et al. The interferons: mechanism of action and clinical applications. FAMA 1991;266: 1375-83.

12 White CW, Wolf SJ, Korones DN, Sondheimer HM, Tosi MF, Yu A. Treatment of childhood angiomatous diseases with recombinant interferon alfa-2a. $\mathcal{F}$ Pediatr 1991 ; 1988: 59-66.

13 Ezekowitz AB, Mulliken JB, Folkmann J. Interferon alfa-2a therapy for lifethreatening hemangiomas of infancy. $N E n g l$

F Med 1992; 326: 1456-63.
14 Fung WE. Interferon alfa-2a for treatment of age-related macular degeneration. Am f Ophthalmol 1991; 112: 349-50. 
Lund-Andersen $\mathrm{H}$. Interferon alfa-2a treatment of patients with subfoveal neovascular macular degeneration: a pilot investigation. Acta Ophthalmol 1993; 71:27-31.

16 Thomas MA, Ibanez HE. Interferon alfa-2a in the treatment of subfoveal choroidal neovascularization. Am $\mathcal{f}$ Ophthalmol 1993; 115: 563-8

17 Ebert EM, Fine AM, Markowitz J, Maguire MG, Starr JS, Fine SL. Functional vision in patients with neovascular maculopathy and poor visual acuity. Arch Ophthalmol 1986; 104: 1009-12.

18 Green WR. Clinicopathologic studies of senile macular degeneration. In: Nicholson DH, ed. Ocular pathology update. New York: Masson, 1980: 115-44.

19 Young RW. Pathophysiology of age-related macular degeneration. Surv Ophthalmol 1987; 31: 291-306.

20 Guyer DR, Tiedman J, Yannuzzi LA, Slakter JS, Parke D,
Kelley J, et al. Interferon-associated retinopathy. Arch Ophthalmol 1993; 111: 350-6.

21 Berkow JW. Subretinal neovascularization in senile macular degeneration. Am 7 Ophthalmol 1984; 97: 143-7.

22 Bressler NR, Bressler SB, Fine SL. Subfoveal neovascular membranes in senile macular degeneration: relationship between membrane size and visual prognosis. Retina 1983; 3: 7-11.

23 Macular Photocoagulation Study Group. Recurrent choroidal neovascularization after argon laser photocoagulation for neovascular maculopathy. Arch Ophthalmol 1986; 104: 50312.

24 Macular Photocoagulation Study Group. Laser Photocoagulation of subfoveal recurrent neovascular lesions in age-related macular degeneration: results of a randomized clinical trial. Arch Ophthalmol 1991; 109: 1242-57. 